\title{
Policy of local excision for early cancer of the colorectum
}

\author{
B. C. MORSON, H. J. R. BUSSEY, AND S. SAMOORIAN \\ From the Department of Pathology, St. Mark's Hospital, London
}

SUMMARY A policy of local excision or total biopsy for early cancer of the colorectum, when this is technically possible, has been described. This is based on thorough histological examination of the excised specimen with special reference to the completeness of surgical excision, the depth of spread of the cancer into the bowel wall, and the histological grade of malignancy. The results of this policy in 119 patients treated by local excision only have been studied. There have been 10 recurrences but only five of these are regarded as policy failures. Because of these good results it is suggested that the policy as described should be regarded as an established alternative to partial colectomy, anterior resection, and abdominoperineal excision in carefully selected patients.

For many years it has been the policy at this hospital to attempt a complete local excision for certain selected cancers of the rectum and distal colon if this were technically possible. Many of these presented as so-called 'malignant polyps'. This is really a form of 'total biopsy' and is followed by a thorough histological examination of the removed specimen to see whether local excision of the cancer was complete or whether there were any other histological criteria present which indicated that a further radical operation was necessary. The object of this paper is to report the results of this policy as practised with increasing frequency over the past 25 years.

\section{Methods}

Histological examination includes an assessment of the following main features: (1) the presence of invasive carcinoma across the line of the muscularis mucosae; (2) the depth of invasion by carcinoma, whether into the submucosal plane (or stalk of a polyp) only, into the muscularis propria or right across the bowel wall into the extramural tissues; (3) the completeness of local excision, as judged by examination of as many sections as required in order to get a complete histological picture of the whole tumour; (4) the grade of malignancy of the invasive carcinoma. This can be categorised as low (well differentiated), average (moderately differentiated), or high (poorly differentiated).

Received for publication 20 May 1977
The histological report indicates whether local excision is 'complete' or 'incomplete'. In some cases growth has been 'at the margin of excision', in which case it has been recorded by us as 'doubtfully complete'. The surgeon's margin of excision is often recognisable by the presence of a diathermy burn which causes a characteristic coagulative necrosis. It may be mentioned here that it is common practice for surgeons to diathermy the site from which a tumour has been removed by local excision in order to destroy any small foci of residual growth which might remain.

It has been the practice to advise local excision only for those patients in whom local excision was complete and the carcinoma was not of a high grade of malignancy. Evidence previously published has shown that the risk of lymph node metastasis having already taken place is very low when direct spread in continuity is confined to the submucosal plane of the bowel wall. The exception is with poorly differentiated adenocarcinomas (Morson, 1966). The decision whether or not to perform a further radical operation was influenced by clinical factors, especially the level of the growth in the rectum (because of the wish to avoid permanent colostomy) and the age and general state of health of the patient.

\section{General results}

One hundred-and-forty-three patients were treated by local excision for carcinoma of the distal colon and rectum between 1948 and 1972. Local excision was the operation of choice at the time because this 
was technically possible for tumours the majority of which were less than $3 \mathrm{~cm}$ across. The proportion of local excision operations to major operations during the period under review was $3.6 \%$ but varied from $1.4 \%$ in $1948-52$, to $7.5 \%$ in $1968-72$ (Table 1 ). The introduction of therapeutic colonoscopy accounts for the even higher figure of $9.4 \%$ in $1973-75$.

Table 1 Proportion of local excisions to major operations for cancer of colorectum (St. Mark's Hospital 1948-72)

\begin{tabular}{lccc}
\hline Period & Major operations & Local excisions & Per cent \\
\hline $1948-52$ & 950 & 13 & $1 \cdot 4$ \\
$1953-57$ & 899 & 16 & $1 \cdot 8$ \\
$1958-62$ & 807 & 24 & $3 \cdot 0$ \\
$1963-67$ & 676 & 40 & $5 \cdot 9$ \\
$1968-72$ & 667 & 50 & $7 \cdot 5$ \\
Total & 3999 & 143 & $3 \cdot 6$ \\
\hline
\end{tabular}

AGE AND SEX

There were 76 men and 67 women with an average age of 66 and 63 years respectively. About one-third of the patients were over 70 years of age at the time of the operation but only $5 \%$ were over 80 years (Table 2). The age range of the series shows only a

Table 2 Local excisions for cancer of the distal colon and rectum: age and sex distribution

\begin{tabular}{|c|c|c|c|c|}
\hline & $\begin{array}{l}\text { Males } \\
\text { (no.) }\end{array}$ & $(\%)$ & $\begin{array}{l}\text { Females } \\
\text { (no.) }\end{array}$ & $(\%)$ \\
\hline $\begin{array}{l}\text { Number of cases } \\
\text { Average age (yr) } \\
70-79 \text { (yr) } \\
80 \text { and over (yr) }\end{array}$ & $\begin{array}{l}76 \\
66\end{array}$ & $\begin{array}{r}53 \\
28 \\
9\end{array}$ & $\begin{array}{l}67 \\
63\end{array}$ & $\begin{array}{r}47 \\
27 \\
4\end{array}$ \\
\hline $\begin{array}{c}\text { Age (yr) } \\
30- \\
40- \\
50- \\
60- \\
70- \\
80- \\
90-\end{array}$ & $\begin{array}{r}1 \\
4 \\
14 \\
29 \\
21 \\
7 \\
-\end{array}$ & $\begin{array}{r}1 \cdot 3 \\
5.2 \\
18 \cdot 5 \\
38 \cdot 2 \\
27 \cdot 6 \\
-\quad 9 \cdot 2\end{array}$ & $\begin{array}{r}3 \\
3 \\
19 \\
21 \\
18 \\
2 \\
1\end{array}$ & $\begin{array}{r}4.5 \\
4.5 \\
28.3 \\
31.4 \\
26.8 \\
3.0 \\
1.5\end{array}$ \\
\hline Total & 76 & $100 \cdot 0$ & 67 & $100 \cdot 0$ \\
\hline
\end{tabular}

very slight bias towards the older age groups (Table 2) by comparison with the St. Mark's series of major operation cases (Bussey, 1977). This is important because it might be thought that local excision could be a favoured procedure as a palliative measure only on grounds of advanced age.

SITE OF TUMOURS (Table 3)

The majority were within reach of the sigmoidoscope but those more proximal were treated by colotomy and local excision.

SITE OF TUMOURS (Table 4)

Although most were under $2.0 \mathrm{~cm}$ in diameter a significant number (26 out of 143 tumours) were
Table 3 Local excisions for cancer of distal colon and rectum: site of tumours

\begin{tabular}{lcc}
\hline Site & Number & Per cent \\
\hline Transverse colon & 1 & $0 \cdot 7$ \\
Sigmoid colon & 28 & $19 \cdot 6$ \\
Rectosigmoid & 10 & $7 \cdot 0$ \\
Upper rectum & 45 & $31 \cdot 4$ \\
Middle rectum & 20 & $14 \cdot 0$ \\
Lower rectum & 39 & $27 \cdot 3$ \\
Total & 143 & $100 \cdot 0$ \\
\hline
\end{tabular}

Table 4 Local excisions for cancer of distal colon and rectum: size of tumours

\begin{tabular}{lcc}
\hline Size $(\mathrm{cm})$ & Number & Per cent \\
\hline Under 1·0 & 13 & $9 \cdot 4$ \\
$1-2$ & 73 & $53 \cdot 0$ \\
$2-3$ & 26 & $18 \cdot 8$ \\
$3-4$ & 15 & $10 \cdot 9$ \\
$4-5$ & 6 & $4 \cdot 3$ \\
Over 5 & 5 & $3 \cdot 6$ \\
Unclassified & 5 & - \\
Total & 143 & $100 \cdot 0$ \\
\hline
\end{tabular}

over $3.0 \mathrm{~cm}$ across. There is obviously considerable bias towards local excision for the smaller tumours but it is important to note that so many were quite large, including five which were more than $5.0 \mathrm{~cm}$ in diameter.

GRADE OF MALIGNANCY

Sixty $(42 \%)$ of the 143 patients had low grade carcinomas, $77(53.8 \%)$ average grade, and six $(4.2 \%)$ tumours of high grade malignancy. This incidence of high grade tumours is much lower than that seen in major operation specimens for rectal cancer (Lockhart-Mummery et al., 1976).

EXTENT OF SPREAD OF CARCINOMA (Table 5) In 115 out of 143 tumours $(80.4 \%)$ the carcinoma had not spread beyond the submucosal plane of the rectal or colonic wall; in 20 cases it had also penetrated into the muscularis propria and in only seven had it just reached into the extramural tissues. These figures accurately reflect the clinical opinion that most of these tumours were 'early' cancers and were suitable for a policy of local excision or total biopsy in the first place.

Table 5 Local excisions for cancer of distal colon and rectum: extent of spread of carcinoma

\begin{tabular}{lrc}
\hline Extent & Number & Per cent \\
\hline Submucosa only & 115 & $81 \cdot 0$ \\
Into muscularis propria & 20 & $14 \cdot 1$ \\
Extramural & 7 & $4 \cdot 9$ \\
Unclassified & 1 & - \\
Total & 143 & $100 \cdot 0$ \\
\hline
\end{tabular}


SURVIVAL RATE

This is given in Table 6. The general results are good but greater significance should be attached to the figures for the series divided up into different categories for the purposes of testing the policy (Table 7).

Table 6 Cancer of distal colon and rectum: survival after local excision only (119 patients)

\begin{tabular}{lll}
\hline $\begin{array}{l}\text { Completeness of } \\
\text { local excision }\end{array}$ & \multicolumn{2}{l}{ Five-year survival rate } \\
\cline { 2 - 3 } & $\begin{array}{l}\text { Crude } \\
(\%)\end{array}$ & $\begin{array}{l}\text { Corrected } \\
(\%)\end{array}$ \\
\hline Complete (91 patients) & 82 & 100 \\
Doubtfully complete (14 patients) & 64 & 96 \\
Incomplete (14 patients) & 57 & 83 \\
\hline
\end{tabular}

Table 7 Local excision only for carcinoma of distal colon and rectum

\begin{tabular}{lccl}
\hline Category & Patients & Recurrences & $\begin{array}{l}\text { Policy } \\
\text { failures }\end{array}$ \\
\hline Complete & 91 & 3 & 3 \\
Doubtfully complete & 14 & 2 & 2 \\
Incomplete & 14 & 5 & NA \\
Total & 119 & 10 & 5 \\
\hline
\end{tabular}

NA: not applicable

\section{Analysis of results by category}

The series of 143 patients is divided into the following categories for the purpose of testing the policy already described: (1) 102 patients in whom local excision was regarded as histologically complete (of these 91 had no further treatment and 11 had a subsequent major operation); (2) 18 patients in whom local excision was reported as doubtfully complete; 14 of these had no further treatment and four had a subsequent major operation; (3) 23 patients in whom local excision was reported as incomplete (of these 14 had no further treatment and nine had a subsequent major operation).

LOCAL EXCISION HISTOLOGICALLY COMPLETE (102 out of 143 cases)

Local excision only

This group is important because 91 of the 102 tumours were considered to be completely removed histologically both at the time of the original report and on subsequent review of the histological sections. The survival rate is excellent, so much so that it is more interesting to look closely at those few (only three out of 91) in whom there was any evidence of recurrence (Table 7). Out of the 102 patients 91 showed invasion into the submucosal plane only; nine had carcinoma invading into the muscularis propria and two just into the extramural tissues.
Only one of the 11 patients with spread beyond the submucosal plane developed a recurrence. All the other 10 were cured by local excision only.

\section{Local excision and further major operation}

In eight cases subsequent review of the histological sections supported the view that local excision was complete but at the time of the operation the records suggest that there was doubt about this, either in the mind of the pathologist (B.C.M.) or on the part of the surgeon. In two cases the carcinoma was originally reported as poorly differentiated and in one the sutures in a colotomy incision parted causing a pericolic abscess and this led to a bowel resection. This adds up to 11 patients who had a bowel resection within 42 days of the local excision but none had any evidence of residual growth in the major operation specimen. Only two died with evidence of recurrence at two years and $3 \frac{1}{2}$ years after treatment (patients 4 and 5 below). They died with carcinomatosis and there is considerable doubt whether 'further major operation' in any way helped them.

\section{Analysis of recurrences}

The first patient had a local excision which was considered complete and no further operation was advised. Five years later a local recurrence was confirmed by biopsy. The subsequent major operation specimen was a Dukes' $\mathrm{Cl}$ case and showed an intramural recurrence with two involved regional lymph nodes. The patient is still alive and well 23 years after the original local excision.

In retrospect the cause of the recurrence could have been the presence of lymphatic permeation in the stalk of the original malignant polyp but it is doubtful whether this would have had any effect on the advice to perform local excision only today any more than 23 years ago. However, this case must be considered as a local excision policy failure despite the fact that the patient was later cured by a major operation.

The second patient had a local excision but two years later developed multiple secondaries in both lungs and died five years later. She had no evidence of local recurrence and there is no way of knowing whether a major operation in the first place would have made any difference. This recurrence could, however, be considered as an example of failure of the policy.

The third patient underwent a local excision for a carcinoma of the middle third of the rectum. Just over two years later a local recurrence was detected. Excision of the rectum was carried out but no residual growth was present in the operation specimen. Unfortunately the patient died on the 
fourth day after operation from gastric dilatation and cardiac failure. This local recurrence must be regarded as a policy failure.

Patients 4 and 5 both had local excision of a moderately differentiated adenocarcinoma which was invading the submucosa only. The major operation specimens removed within a fortnight of the local excision contained no residual carcinoma. Neither patient was subsequently seen at St. Mark's Hospital but death occurred at one year 11 months and three years five months after operation. In each case the death certificate gave the cause of death as 'carcinomatosis'. There is no evidence that this 'carcinomatosis' arose from the rectal malignancy but, in the absence of any evidence to the contrary, this has been assumed. These two cases cannot be regarded as policy failures, because of the absence of any carcinoma in the major operation specimens.

\section{LOCAL EXCISION DOUBTFULLY COMPLETE (18 patients) \\ Local excision only}

In these patients the histological evidence suggested that local removal was 'doubtfully complete' because carcinoma was present very close to or at the margin of surgical excision. Despite this, no further operation was recommended in six patients on the grounds of advanced age (75-90 years). In a further six cases diathermy at the base of the lesion was considered to be sufficient further local treatment, and in another local excision was considered sufficient because the patient also had a primary carcinoma of the lung. Finally, there was one case in which local removal was originally judged as complete but subsequent review placed it in the 'doubtful' category. These 14 patients who had local excision only had a crude five-year survival rate of $64.3 \%$ and a corrected five-year survival rate of $95.7 \%$. There was evidence of recurrence in only two patients (Table 7). One of these was aged 75 years at the time of local excision and died at age 80 years with local recurrence. Theoretically, at least, this patient would have been helped by a major operation but at the time this was considered inadvisable on grounds of age and indifferent general health. The other patient had a local excision for a welldifferentiated adenocarcinoma which had spread no further than the submucosal layer. Liver and lung secondary deposits were found 16 months after operation and he died 18 months later. Both these cases for the purpose of this study have been classed as 'policy failures' (Table 7).

\section{Local excision and further major operation}

Out of 18 patients four had a further radical operation because local excision was judged to be doubt- fully complete. Two of these major operation specimens contained residual growth at the site of local removal. One had moderately differentiated carcinoma spreading into the muscularis propria but no lymph node deposits. This patient died five years after operation with secondary deposits in the abdominal cavity. The other specimen showed spread no further than the submucosal plane with no lymph nodes involved and the patient is still alive 17 years after operation. In the other two major operation specimens there was no residual tumour so, in fact, local excision had been complete.

LOCAL EXCISION HISTOLOGICALLY INCOMPLETE (23 out of 143 cases)

\section{Palliative local excisions}

There were 14 who had no further surgical treatment despite the fact that local excision was thought to be incomplete. The reasons for these palliative local excisions were the presence of hepatic metastases (two patients), advanced age and poor general condition (seven patients) and, in retrospect, what appeared to be a 'surgical gamble' (four patients). In one case the necessary information was not available for the record. The average age was just over 70 years and $20 \%$ were over 80 years. Moreover, in five of the 14 the carcinoma had spread beyond the submucosal plane. They were clearly older and had rather more advanced malignancy than the average of the whole series. Despite the fact that these were considered to be palliative operations, there have been only five recurrences out of 14 patients (Table 7). The other nine are either alive, after more than five years since the local excision, or have died from causes unrelated to the bowel cancer.

\section{Local excision and further major operation}

Out of the 23 patients who had histologically incomplete local excisions nine had a further major bowel resection within $\mathbf{4 2}$ days of the local operation. Only three of these surgical specimens contained residual growth. In every one there were lymph node deposits but no residual growth at the site of the former local excision. Two were poorly differentiated adenocarcinomas.

\section{Discussion}

The results in the largest and most important group of 91 'local excision only' cases are excellent with only three recurrences which could be regarded as 'policy failures' (Table 7) and one of these was subsequently cured at a later date by a major operation. Study of the 11 cases of 'local excision with complete removal' who had further major operations suggests that the latter were all unneces- 
sary because there was no residual growth at the primary site or in the regional lymph nodes. There were two patients in this group who died but the evidence does not suggest that major operation in any way affected the outcome and they would have probably been just as well off with 'local excision only'. These 11 cases make a good control series and provide support for the local excision policy as described.

The lesson to be learned from the group of 'local excision doubtfully complete' cases is that the policy of diathermy treatment to the base of the locally removed tumour can be effective in removing any residual carcinoma at the primary site. Study of the recurrences confirms that local excision alone is not the treatment of choice for poorly differentiated adenocarcinoma or for local excision cases in which there is doubtfully complete removal of carcinoma which has spread deeply into the muscularis propria. In retrospect, out of the 18 'doubtfully complete' local excision patients only four really required a further major operation and it is questionable whether one of these benefited in so far as length of survival was concerned. There were two patients who, as it turned out, had unnecessary major operations after local excision.

Analysis of the histologically incomplete local excisions shows that the observation was inaccurate for all but five cases because either the patients were cured or had no evidence of residual growth at the primary site in the major operation specimen, although three had lymph node deposits. The observation 'histologically incomplete' has been made when growth was seen at the limit of excision on careful microscopic examination of the locally excised tumour. It is clear from the results of treatment of this group that, although this was an accurate observation by the pathologist, all tumour had, in fact, been removed by the surgeon. How can this be explained? Probably by the practice of diathermy of the operation site at the time of local excision which destroyed any residual carcinoma which may have been present. The fact that two out of three cases with nodal metastases were poorly differentiated carcinomas again supports that part of the policy which states that poorly differentiated tumours are unsuitable for local excision only. The nine patients who had a further major operation after histologically incomplete local excision provide another control group for judging the basis on which a policy of local excision only can be practised. In retrospect, only three of these in fact needed a further operation because they had lymph node metastases, but no residual growth in the primary site. So in all of the nine patients further operation failed to confirm the first report that local excision was incomplete and in two the observation that the carcinoma was poorly differentiated anticipated the presence of lymph node deposits. If the third patient had been treated by local excision only it would have turned out to be a policy failure. Thus, implementation of the local excision only policy as described would have led to only one failure out of seven cases.

The policy of local excision for early colorectal cancer as described here was initiated by the studies of Lockhart-Mummery and Dukes (1952) and further established by Carden and Morson (1964) and Morson (1966). These papers, together with the recent report by Shatney et al. (1976), have mostly described the application of this policy to the treatment of so-called 'malignant polyps', whereas it is now clear that the size and shape of the tumour as well as the presence or absence of a stalk is largely irrelevant. Certainly, the presence of a pedicle makes 'polypectomy' a relatively easy procedure, even through the colonoscope, but recently introduced surgical techniques of local excision are now available which have made it possible to remove much larger tumours from the distal colon and rectum than hitherto (Parks, 1966, 1968; Parks and Stuart, 1973; Mason, 1976). Now that these technical problems are being overcome it is important to emphasise that it is not the size or shape of the tumour but the depth of spread of any cancer into the bowel wall and its histological grade of malignancy which have greatest importance in deciding whether or not local excision is sufficient treatment. If it is technically possible to remove a tumour by complete local excision, then such a 'total biopsy' should be performed in the first place. Whether or not it is decided to perform a further major operation depends on close collaboration between surgeon and pathologist.

The selection of patients suitable for local excision depends on the judgement of the surgeon or endoscopist. For tumours within reach of the examining finger the development of a system of clinical staging as suggested by Mason (1976) should be explored further. There is nothing to be lost by 'total biopsy' in the first place, except the time it takes for thorough examination of the specimen by the pathologist. Complete local excision has special advantages for the older patients and for those who for reasons of poor general health are unsuitable candidates for a major surgical procedure. When considering the balance of risks it must be remembered that there is a significant postoperative mortality after major operations on the large bowel, even in the hands of the most experienced surgeons, and this risk is particularly high in patients over 70 years of age (Whittaker and Goligher, 1976). 
Theoretically, those $15 \%$ of rectal and colonic cancers treated by major surgery which turn out to be Dukes' A cases could all have been just as successfully treated by local excision, if this were technically possible. Certainly, it should be possible in the future to treat more patients with 'early' colorectal cancer by local excision. It is not clear why there has been an increasing number of such operations performed at St. Mark's in recent years but confidence in the policy is probably one factor. It is also likely that improved techniques of investigation are producing more 'early' cancers than hitherto. The introduction of air contrast radiography (Young, 1964) and therapeutic colonoscopy(Williams et al., 1973) are major advances in this respect. It can be emphasised here that the expression 'early cancer' is not meant to imply a stage in histogenesis but cancer which is essentially curable in an analogous way to the use of the expression 'early gastric cancer' in Japan (Murakami, 1971).

We are grateful to the Cancer Research Campaign and the St. Mark's Research Foundation for financial support. Our thanks are also due to the surgical staff of the hospital, and Mr Lloyd Soodeen for technical assistance.

\section{References}

Bussey, H. J. R. (1977). Unpublished data.

Carden, A. B. G., and Morson, B. C. (1964). Recurrence after local excision of malignant polyps of the rectum. Proceedings of the Royal Society of Medicine, 57, 559-561.

Lockhart-Mummery, H. E., and Dukes, C. E. (1952). The surgical treatment of malignant rectal polyps. Lancet, 2, 751-756.
Lockhart-Mummery, H. E., Ritchie, J. K., and Hawley, P. R. (1976). The results of surgical treatment for carcinoma of the rectum at St. Mark's Hospital from 1948-1972. British Journal of Surgery, 63, 673-677.

Mason, A. York (1970). The place of local resection in the treatment of rectal carcinoma. Proceedings of the Royal Society of Medicine, 63, 1259-1262.

Mason, A. York (1976). Rectal cancer: the spectrum of selective surgery. Proceedings of the Royal Society of Medicine, 69, 237-244.

Morson, B. C. (1966). Factors influencing the prognosis of early cancer of the rectum. Proceedings of the Royal Society of Medicine, 59, 607-608.

Murakami, T. (1971). Pathomorphological diagnosis: definition and gross classification of early gastric cancer. In Early Gastric Cancer, Gann Monograph on Cancer Research II, pp. 53-55. Edited by T. Murakami. University of Tokyo Press: Tokyo.

Parks, A. G. (1966). Benign tumours of rectum, in Clinical Surgery, vol. 10, pp. 541-548. Edited by C. Rob, R. Smith, and C. Naunton Morgan. Butterworth: London.

Parks, A. G. (1968). A technique for excising extensive villous papillomatous change in the lower rectum. Proceedings of the Royal Society of Medicine, 61, 441-442.

Parks, A. G., and Stuart, A. E. (1973). The management of villous tumours of the large bowel. British Journal of Surgery, 60, 688-695.

Shatney, C. H., Lober, P. H., Gilbertson, V., and Sosin, H. (1976). Management of focally malignant pedunculated adenomatous colorectal polyps. Diseases of the Colon and Rectum, 19, 334-341.

Whittaker, M., and Goligher, J. C. (1976). The prognosis after surgical treatment for carcinoma of the rectum. British Journal of Surgery, 63, 384-388.

Williams, C., Muto, T., and Rutter, K. R. P. (1973). Removal of polyps with fibreoptic colonoscope: a new approach to colonic polypectomy. British Medical Journal, 1, 451-452.

Young, A. C. (1964). The Malmö enema at St. Mark's Hospital: a preliminary report. Proceedings of the Royal Society of Medicine, 57, 277-278. 